\title{
Parallel Solid-Phase Synthesis of lodinated Analogues of Rimonabant
}

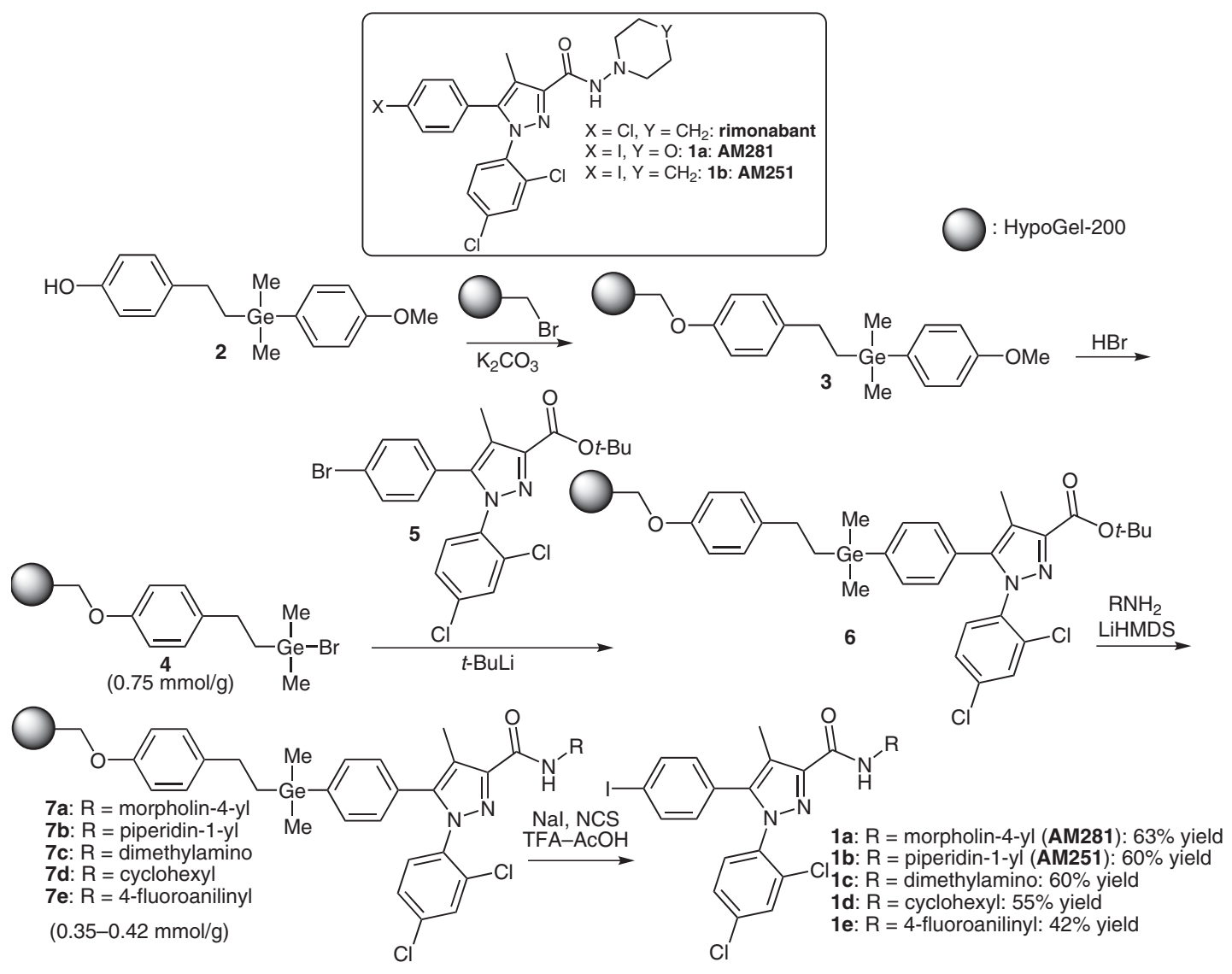

Significance: A novel method for the parallel solid-phase synthesis of iodinated analogues of the $\mathrm{CB}_{1}$ receptor inverse agonist rimonabant was described. HypoGel-bound 1,5-diarylpyrazole tert-butyl ester $\mathbf{6}$ was prepared by employing HypoGel-bound gelmanium bromide 4 via transmetalation. Parallel amidation of $\mathbf{6}$ with hydrazines and amines gave HypoGel-bound 1,5-arylpyrazolyl hydrazides/amides $\mathbf{7 a - e}$. Cleavage of the $\mathrm{Ge}$ linker with concomitant ipso-iodination afforded iodinated rimonabant analogues 1a-e (5 examples, 42-63\% yield, 1-6 h).
Comment: Rimonabant (marketed as Acomplia) is a $\mathrm{CB}_{1}$ receptor inverse agonist first approved for the treatment of obesity by European Medicines Agency in 2006, and then withdrawn from the market in 2008 following the emergence of psychiatric disorders among patients. Various ${ }^{11} \mathrm{C}$ labeled, ${ }^{18} \mathrm{~F}$-labeled, and ${ }^{123 / 124}$ I-labeled rimonabant derivatives (e.g., 1a: $\left[{ }^{123}\right.$ ] AM281 and 1 b: [123] AM251) have proved to be viable for positron emission tomography (PET) and single photon emission computerized tomography (SPECT) imaging of central nervous system (CNS) activity.

sYNFACTS Contributors: Yasuhiro Uozumi, Yoichi M. A. Yamada, Maki Minakawa

Synfacts 2010, 1, 0115-0115 Published online: 21.12.2009

DoI: 10.1055/s-0029-1218442; Reg-No.: Y13609SF 